Article

\title{
Cognitive Component of the Image of a Rural Tourism Destination as a Sustainable Development Potential
}

\author{
Ksenija Leković ${ }^{1}$, Slavica Tomić ${ }^{1}$, Dražen Marić ${ }^{1, *}$ and Nikola V. Ćurčić ${ }^{2}$ (i) \\ 1 Faculty of Economics in Subotica, University of Novi Sad, 24000 Subotica, Serbia; \\ ksenija.lekovic@ef.uns.ac.rs (K.L.); slavica.tomic@ef.uns.ac.rs (S.T.) \\ 2 Institute of Agricultural Economics, 11000 Belgrade, Serbia; nikola_c@iep.bg.ac.rs \\ * Correspondence: drazen.maric@ef.uns.ac.rs; Tel.: +381-24-628-135
}

Received: 27 October 2020; Accepted: 5 November 2020; Published: 12 November 2020 updates

\begin{abstract}
Sustainable tourism should maintain a high level of tourist satisfaction, so identifying components of tourism destination image plays an important role in destination management and marketing. This study aims to explore issues related to the image of a rural tourism destination, with the focus on the cognitive component. It also aims to analyze three dimensions of the cognitive component: functional, mixed, and psychological. Furthermore, this study gives the answer to the question of which dimension of the cognitive component makes the most significant impact on the general image of a rural tourism destination. The sample comprised 562 respondents. Data analysis included exploratory factor analysis (EFA), confirmatory factor analysis (CFA), and structural equation modeling (SEM). The results indicate the existence of three dimensions of the cognitive component, and it can be concluded that the psychological dimension of the cognitive component has the most significant impact on the general image of a rural tourism destination.
\end{abstract}

Keywords: sustainable development; sustainable tourism development; rural tourism; image of a rural tourism destination; cognitive component; dimensions of the cognitive component

\section{Introduction}

Sustainable development represents a concept that refers to the potential of productive activities to meet the contemporary needs without jeopardizing the opportunities of posterity [1]. Tourism, as one of the global engines of development, results in tourism impacts, which can be classified into three categories: economic, environmental, and sociocultural [2]. These impacts can either be positive (job creation, enhancement in the quality of life of local residents, an improved public image of the destination, protection of cultural heritage, etc.) or negative (overcrowding, disruption of local lifestyle, environmental damage, intensive use of resources, etc.) [1,3,4]. As a result of its dynamic nature, tourism offers new destinations and new forms of travel but on the other hand requires new approaches to management, new resources, and constant innovations [5]. Suitable balance between these impacts is reflected in sustainable tourism. Sustainable tourism respects the wholesomeness of natural, social, and economic setting by rationally exploiting natural and cultural heritage while offering posterity and equal opportunities to profit from the same resources [6]. Therefore, by reducing energy consumption and pollution rate, the protected environment and the preserved cultural heritage can lead to the sustainable tourism sector [7]. Principles of sustainable tourism development are applicable to all forms of tourism. Thus, the sustainable hospitality industry is a key indicator of sustainable development in rural regions [8].

According to Okech et al. [9], it is important to advance tourism in rural regions because it increases people's involvement in the advancement of the travel and hospitality industry and brings wider benefits to rural areas. Moreover, the travel and hospitality industry, especially rural tourism, can be 
beneficial to people who live in urban areas and look for relaxation. For those consumers, rural tourism is eco-friendly travel for entertainment and enjoyment in nature [10]. At the same time, rural tourism can be beneficial to people who live in rural areas as a means of earning a living. It also reduces the migration of population from these regions and creates new employment opportunities [11-13]. Rural areas can attract consumers from urban areas by the means of establishing a bond with their cultural, historical, ethnic, and geographical roots [14]. Furthermore, rural areas represent places where the traditions, heritage, and natural beauty meet [15]. Sustainability in rural regions should merge four factors: ecological, economic, social, and cultural [16]. Therefore, rural tourism can be considered a synonym for sustainability [12]. According to Irshad [17] and Lane [18], rural tourism can be regarded as an umbrella concept because it covers various forms of travel and hospitality industry, such as ecotourism, farm tourism, agritourism, adventure-seeking, equestrian tourism, and food and wine tourism. Thus, in line with the umbrella concept, rural tourism includes all forms of activities undertaken by consumers in rural areas that contain some elements related to traditions, culture, and hospitality [6]. Authenticity and tradition are the main characteristics that separate these forms of tourism from other selective forms of tourism [19].

Success of rural tourism depends on many factors, which must ensure tourist satisfaction [20]. First of all, this form of tourism, which includes small villages with attractive landscapes, thermal springs, rivers, and lakes, enables consumers to reunite with nature and local culture [21,22]. It also offers a peaceful experience, low costs, and healthy challenges [23]. Rural tourism destinations can be described as packages of many different facilities and services that determine their attractiveness. On the other hand, tourists perceive a rural tourism destination as a concept that comprises variety of products and services. During their stay, tourists "consume" the destination as an intrinsic experience composed of multiple individual experiences and external elements [24]. This process results in a composite image referring to the possible favorable or unfavorable evaluation of the destination. The image of a destination can be defined as a set of impressions, ideas, expectations, and emotional thoughts a tourist has of a specific destination [25,26]. Authors Lai and Li cite the most commonly used terms for defining the image of a destination: impression, perception, belief, idea, and representation [27]. According to Agapito et al. [28], the image of a destination plays a substantial part in tourist behavior in different phases of the buying process: (1) in the decision-making process with regard to opting for a particular destination, (2) in the process of evaluating the actual experience against previous expectations, and (3) in the process of revisiting the destination and spreading positive/negative word-of-mouth. Thus, the image of a rural tourist destination makes a notable impact on tourist's behavior, preferences, and the intention to revisit that particular destination.

The explanation of tourism destination image starts from the multi-attribute concept [25,29-33]. According to this concept, tourism destination image constitutes three interrelated components: (1) cognitive, (2) affective, and (3) conative or behavioral. The cognitive component is the aggregate of what a tourist knows or believes about a destination [34]. The second component of this concept, the affective component, denotes the emotional responses that reflect the tourist's feelings towards the destination [35]. The cognitive component guides the affective one. In other words, it is an antecedent of the affective component because tourists' evaluative responses stem from their acquaintance with the particular rural tourism destination [36]. Finally, the combination of these two components produces a general image related to the positive/negative evaluation of the destination-the conative component. This component represents how and why the tourist's knowledge and feelings contribute to the selection of a particular destination. It is formed when the destination selection is completed and a decision is made [37,38]. Thus, the cognitive and affective components represent tourists' subjective associations linked to a destination, whereas the conative component outlines the desired future situation-revisit, recommendation, and positive word-of-mouth. Besides own experience (as a primary source), opinions of other tourists communicated through word-of-mouth represent the main secondary source of information upon which decision can be made [39]. 
The objective of this particular study was to define and validate the dimensions that make up the cognitive component of the image of a rural tourist destination. According to Chen [40], dimensions of the cognitive component are easier to render and implement, so it is crucial for destination managers and marketers to know which dimensions have the most significant impact on tourists' future behavior. Findings of several studies show that both cognitive and affective components influence tourists' behavioral intentions. However, the immediate consequence of the cognitive component is greater than the impact of the affective one $[20,29,41,42]$. This study applied the composition of a cognitive component, which consists of three dimensions. These dimensions are: (1) functional—based on more tangible sensations, such as surroundings, lodging and price levels; (2) psychological—based on more abstract attributes, such as ambience and sociability; and (3) mixed-based on characteristics of a destination that are between functional and psychological, such as gastronomy [43].

\section{Materials and Methods}

The general objective of this study was to look into the structure of the cognitive image of a rural tourism destination, analyzing its dimensions (functional, psychological, and mixed) and the impact that they make on the general image. The general aim is indicated in two research objectives:

- $\quad$ Research objective 1: To verify the existence of three dimensions of the cognitive image of a rural tourism destination: functional, mixed, and psychological dimensions.

- $\quad$ Research objective 2: To analyze which dimension of the cognitive component of the image of a rural tourist destination makes the most significant impact on the general image.

A structured questionnaire designed for the purpose of this study was distributed to tourists who spent their holiday on a farm or in a winery in the Province of Vojvodina. The convenience sampling method was implemented having previously confirmed that each potential respondent had met the two requirements: (a) that he/she had visited a farm/winery in the Province of Vojvodina in the past two years and (b) that he/she was over 18 years of age. Farms and wineries in the Province of Vojvodina were selected as rural tourism destinations because Vojvodina is a region exemplary of rural tourism with its natural beauty in combination with culture, tradition, and specific gastronomy. Data were gathered in the months of April and May 2020. The questionnaire was distributed online. Initially, 572 questionnaires were collected, but some of them had to be disregarded because they were not filled in correctly, eventually producing a sample of 562 respondents.

The sample profile is presented in Table 1 . Table 1 indicates that $62.6 \%$ of the respondents were male, and the remaining $34.4 \%$ were female. At the time of the research, most respondents were between 18 and 29 years of age (36.7\%) and had a bachelor's degree (51.8\%). The majority lived in four person households (33.6\%) and had a household net monthly disposable income between 601 and 900 euros $(24.6 \%)$.

The data showed that most of the respondents visit rural tourism destinations once or twice a year $(34.2 \%)$, most often with their families $(57.8 \%)$. The Internet is the most common source of information when planning a trip $(49.6 \%)$.

The research was conducted by means of a structured questionnaire containing three parts. The first part dealt with socio-demographic characteristics, the second part contained statements about trip characteristics, and the third part referred to dimensions of the cognitive component of the image of a rural tourist destination and the general image of the destination. The third part was adapted from Polo Pena et al. and Alcaniz et al. [43,44] It included three dimensions (functional, mixed, and psychological) of the cognitive component of the image of a rural tourist destination. Each dimension comprised six items: (a) the functional dimension: It is a nice/beautiful place with attractive natural scenery, There are many historical monuments/sites/museums, Tourists can enjoy fairs/festivals/wine routes, Tourists can undertake different activities in the countryside, The availability of accommodation is good, The local transport is good; (b) the mixed dimension: This place is environmentally friendly, The cleanliness and hygiene are good, The offer of local products on the local 
markets is good, Partaking in the local gastronomic activities/tours is good, Tourists become familiar with the local culture, Tourists can engage in social interactions with members of the local community; and (c) the psychological dimension: It is a quiet/peaceful place, Staff and members of the local community provide tourists with warm welcome, It offers personalized service to tourists, It has quality services, It offers good value for money, There is high quality accommodation. This part contained 18 statements reflecting the three dimensions. The questionnaire used a five-point Likert-type scale, which ranged from 1 ("strongly disagree") to 5 ("strongly agree"). The general image was measured by means of a single five-point scale, from highly unfavorable (1) to highly favorable (5).

Table 1. Profile of survey respondents $(n=562)$.

\begin{tabular}{|c|c|}
\hline Variables & Percent (\%) \\
\hline \multicolumn{2}{|l|}{ Gender } \\
\hline Female & 37.4 \\
\hline Male & 62.6 \\
\hline \multicolumn{2}{|l|}{ Age } \\
\hline $18-29$ & 36.7 \\
\hline $30-39$ & 29.2 \\
\hline $40-49$ & 19.8 \\
\hline $50-59$ & 10.1 \\
\hline$\geq 60$ & 4.3 \\
\hline \multicolumn{2}{|l|}{ Education level } \\
\hline Elementary school & 0.4 \\
\hline Secondary school & 17.3 \\
\hline Bachelor's degree & 51.8 \\
\hline Master's degree & 18.5 \\
\hline Doctoral degree & 12.1 \\
\hline \multicolumn{2}{|l|}{ Net monthly disposable income per household } \\
\hline$\leq 300$ euro & 5.9 \\
\hline 301-600 euro & 22.1 \\
\hline $601-900$ euro & 24.6 \\
\hline 901-1200 euro & 19.2 \\
\hline 1201-1500 euro & 10.7 \\
\hline$>1500$ euro & 17.6 \\
\hline \multicolumn{2}{|l|}{ Household composition (no. of members) } \\
\hline 1 & 9.8 \\
\hline 2 & 19.8 \\
\hline 3 & 22.6 \\
\hline 4 & 33.6 \\
\hline$\geq 5$ & 14.2 \\
\hline \multicolumn{2}{|l|}{ Frequency of engaging in rural tourism } \\
\hline Once every two or three years & 26.9 \\
\hline Once or twice a year & 34.2 \\
\hline Three or four times a year & 15.1 \\
\hline More than four times a year & 23.8 \\
\hline \multicolumn{2}{|l|}{ Travel companions } \\
\hline Alone & 1.6 \\
\hline Partner & 18.3 \\
\hline Family & 57.8 \\
\hline Friends & 21.2 \\
\hline Other & 1.1 \\
\hline \multicolumn{2}{|l|}{ Information sources used to plan the trip } \\
\hline The Internet & 49.6 \\
\hline Recommendations of friends and/or relatives & 32.7 \\
\hline Own experience & 13.9 \\
\hline Newspapers/magazines/catalogues & 0.5 \\
\hline Television & 0.4 \\
\hline Travel agencies & 2.8 \\
\hline
\end{tabular}


Data were analyzed in two steps. First, exploratory factor analysis (EFA) was undertaken to determine the structure of the cognitive component of rural tourist destination image. Second, confirmatory factor analysis (CFA) was conducted to investigate whether the established dimensionality and factor-loading pattern fit well. Structural equation modeling (SEM) was used to examine which dimension has the most significant impact on the general image of the rural tourist destination. Data were processed with SPSS 21.0 and AMOS 21.0 statistical packages.

\section{Results}

In order to address the first research objective, we started with EFA by considering all 18 items (see Table 2 for details) measuring the three dimensions of the cognitive component of the image of a rural tourist destination: functional, mixed, and psychological. Each dimension was measured using six items. The statistical criteria in this study were met. The KMO value for the cognitive component of the image of a rural tourist destination was $0.957>0.60$ [45], which confirmed that there was an adequate number of items for each factor. Furthermore, the value of Bartlett's test of sphericity $[\chi 2(113)=9168.38 ; p<0.001]$ was significant, rejecting the null hypothesis that the correlation matrix was an identity matrix. Based on the results of the initial exploratory factor analysis, there were five items (FUNCT 3, MIX 1, MIX 2, MIX 3, MIX 5) that loaded on two factors in the preliminary three-factor structure.

Table 2. Dimensions and items of the cognitive component of the image of a rural tourist destination.

\begin{tabular}{ll}
\hline \multicolumn{1}{c}{ Dimensions } & \multicolumn{1}{c}{ Items } \\
\hline FUNCT: Functional & Natural environment (FUNCT1) \\
& Historical sights, monuments, museums (FUNCT2) \\
& Fairs, festivals, wine routes (FUNCT3) \\
& Offer of activities in nature (FUNCT4) \\
& Availability of accommodation (FUNCT5) \\
& Local transport (FUNCT6) \\
& Environment (MIX1) \\
& Cleanliness and hygiene (MIX2) \\
MIX: Mixed & Local products offer (MIX3) \\
& Gastronomy (MIX4) \\
& Local culture (MIX5) \\
& Connection with the local population (MIX6) \\
& Tranquility (PSYCHO1) \\
& Friendliness/hospitality (PSYCHO2) \\
& Customized offer (PSYCHO3) \\
& Quality services (PSYCHO4) \\
& Value for money (PSYCHO5) \\
& Quality accommodation (PSYCHO6) \\
\hline
\end{tabular}

After deleting five items, which cross-loaded on two factors, the final three-factor structure in this study was composed of 13 items. As shown in Table 3, six items for factor 1 represented the psychological dimension, five items for factor 2 represented the functional dimension, and two items for factor 3 represented the mixed dimension. Two factors (the psychological and functional dimension) had eigenvalues greater than one. Although the third factor (the mixed dimension) had an eigenvalue below 1 , more precisely 0.645 , it contributed with $4.964 \%$ to the total explained variance. The percentages explained by the psychological dimension were $58.436 \%$, whereas the functional dimension explained $12.156 \%$ of the variance of the cognitive component of the image of a rural tourist destination. The dimension matrix after promax rotation was applied to ascertain which items were more relevant to each factor. In this research, all proposed 13 items for measuring dimensions of the cognitive component of the image of a rural tourist destination were catalogued by high loading factors in a range stretching from 0.667 to $0.933(>0.50)$. 
Table 3. Percentage of variances, eigenvalues, and factor loadings of dimensions of the cognitive component of the image of a rural tourism destination.

\begin{tabular}{ccccc}
\hline Constructs & Items & Eigenvalue & \% of Variance & Factor Loading \\
\hline \multirow{5}{*}{ PSYCHO } & PSYCHO4 & & & 0.933 \\
& PSYCHO6 & & \multirow{2}{*}{58.436} & 0.900 \\
& PSYCHO3 & \multirow{2}{*}{7.957} & & 0.897 \\
& PSYCHO5 & & 0.879 \\
& PSYCHO2 & & & 0.857 \\
& PSYCHO1 & & & 0.730 \\
\hline \multirow{2}{*}{ FUNCT } & FUNCT6 & & \multirow{2}{*}{12.156} & 0.894 \\
& FUNCT5 & \multirow{2}{*}{1.580} & & 0.872 \\
& FUNCT4 & & 0.828 \\
& FUNCT2 & & & 0.724 \\
\multirow{2}{*}{ MIX } & FUNCT1 & & \multirow{2}{*}{4.964} & 0.667 \\
& MIX6 & \multirow{2}{*}{0.645} & & 0.855 \\
\hline
\end{tabular}

In this study, EFA suggested a three-factor structure for the dimensions of the cognitive component of the image of a rural tourism destination. CFA was conducted to verify the factorial validity of the dimensions of the cognitive component of the image of a rural tourism destination. CFA can produce additional evidence related to the appropriateness of the proposed model with regard to the configuration of the factors recognized via EFA. The authors compared the models by means of chi-square $\left(\chi^{2}\right), \chi^{2} / \mathrm{df}$, root mean square error of approximation (RMSEA), goodness-of-fit index (GFI), normed fit index (NFI), Tucker-Lewis index (TLI) and comparative fit index (CFI). A value of $\chi^{2} / \mathrm{df} \leq 5$ is considered acceptable on samples larger than $200[46,47]$. A model that has a CFI and TLI above 0.95, RMSEA of less than 0.08 , and GFI and NFI above 0.9 is considered to fit the data well $[48,49]$.

Table 4 lays out the model specifications for the post hoc CFA. Goodness-of-fit statistics for the initial first-order model reveal that incorporation of the error covariance between FUNCT5 and FUNCT6 (E5 and E6), as well as PSYCHO1 and PSYCHO2 (E13 and E14), made a substantially large improvement to model fit. The factor structure in three-factor model with invariance error achieved adequate model fit $\left(\chi^{2}=204.295, \chi^{2} / \mathrm{df}=3.405\right.$, RMSEA $=0.065, \mathrm{GFI}=0.948, \mathrm{NFI}=0966, \mathrm{TLI}=0.968$ and CFI $=0.975$ ). Therefore, the model of CFA laid out in Figure 1 is the finalized measurement model that indicates the structure of the cognitive component of the image of a rural tourism destination. In Figure 1, each observed variable (FUNCT1, FUNCT2, FUNCT4, FUNCT5, FUNCT6, MIX4, MIX6, PSYCHO1, PSYCHO2, PSYCHO3, PSYCHO4, PSYCHO5, PSYCHO6) has an error term (E1-E18) or measurement error, which reflects their adequacy in measuring the related underlying factors (FUNCT, MIX, PSYCHO). All factor loadings of the three dimensions ranged from 0.63 to 0.94 . The results showed that the factor loadings exceeded the desirable standard of 0.50 [50].

Table 4. Model fit statistics for each hypothesized factor model.

\begin{tabular}{cccccccc}
\hline Model & $\chi^{2}$ & $\chi^{2} / \mathbf{d f}$ & RMSEA & GFI & NFI & TLI & CFI \\
\hline $\begin{array}{c}\text { First-order without } \\
\text { invariance error }\end{array}$ & 296.650 & 4.785 & 0.082 & 0.920 & 0.950 & 0.950 & 0.960 \\
\hline $\begin{array}{c}\text { First-order with } \\
\text { invariance error }\end{array}$ & 204.295 & 3.405 & 0.065 & 0.948 & 0.966 & 0.968 & 0.975 \\
\hline
\end{tabular}




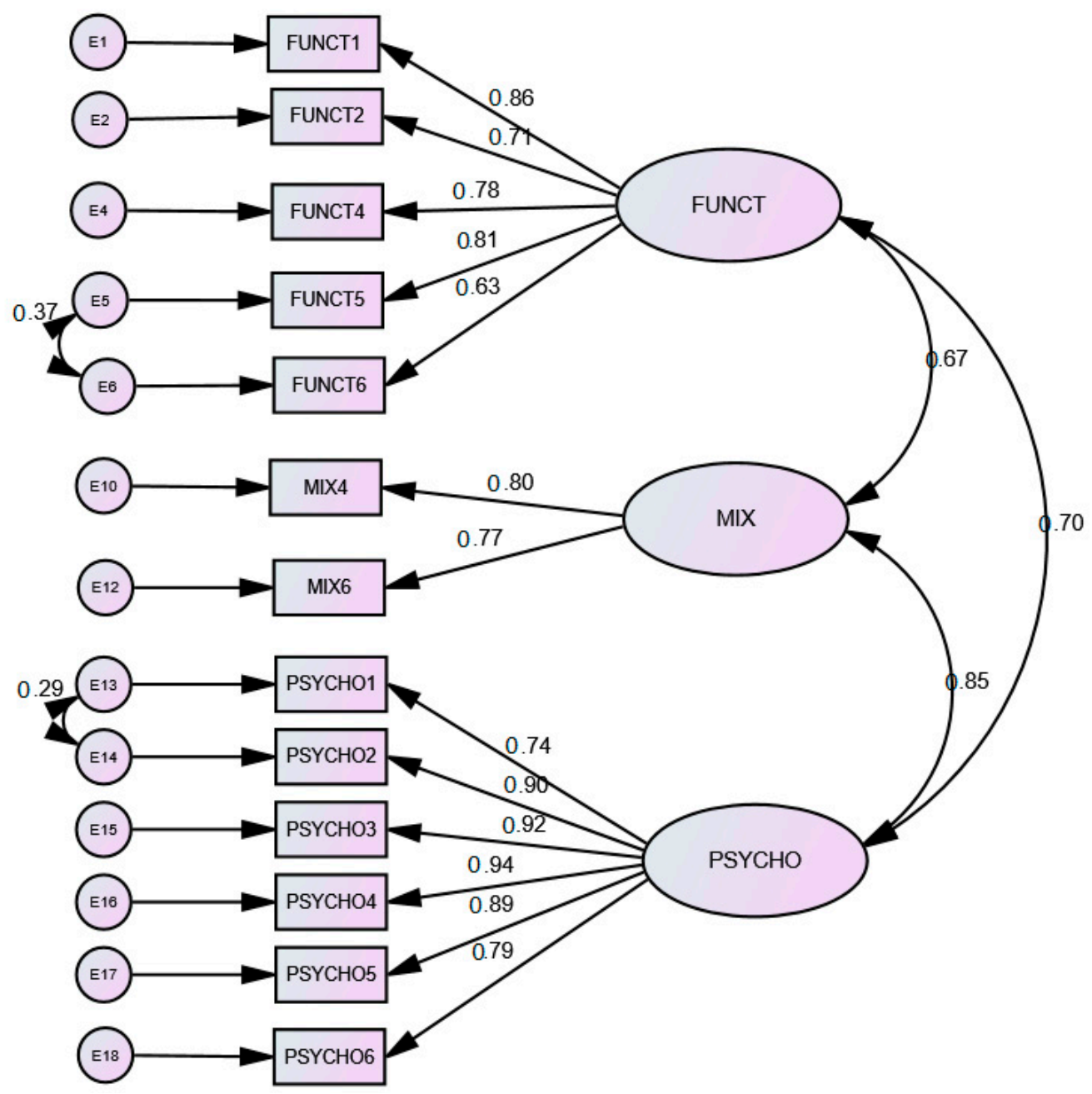

Figure 1. Confirmatory factor analysis—-first-order model with invariance error.

The authors evaluated the measurement model through analysis of reliability, convergent, and discriminant validity (Table 5).

Table 5. Results of reliability, convergent, and discriminant validity testing.

\begin{tabular}{ccccccc}
\hline & CA & CR & AVE & FUNCT & MIX & PSYCHO \\
\hline FUNCT & 0.880 & 0.899 & 0.643 & 0.802 & & \\
\hline MIX & 0.759 & 0.781 & 0.642 & 0.493 & 0.801 & \\
\hline PSYCHO & 0.947 & 0.948 & 0.755 & 0.585 & 0.664 & 0.869 \\
\hline
\end{tabular}

The authors assessed reliability by means of Cronbach's $\alpha$ (CA) and composite reliability (CR). Hair et al. [50] state that both Cronbach's $\alpha$ and composite reliability values for a construct must be higher than 0.7 for the construct to be deemed reliable. Table 5 clearly shows that all the constructs were reliable, as values for both Cronbach's $\alpha$ and composite reliability were well obviously above 0.7. The authors also assessed convergent validity by means of the average variance extracted (AVE). Hair et al. [50] claim that the AVE for every construct in the model must be above 0.5 for a measurement model to show sufficient convergent validity. It is evident from Table 5 that convergent validity was provided as AVEs for all constructs were higher than 0.5 . Discriminant validity was analyzed using the Fornell-Larker criterion. The Fornell-Larker criterion prescribes that the AVE of all latent constructs should be higher than the highest squared correlations between any other construct, and the loadings 
of all indicators should be higher than all their cross-loadings [51]. Table 5 shows that each indicator loaded its highest values on its respective construct. The square root of the AVEs for all constructs was greater than the cross-correlation with other constructs. Therefore, the results laid out in the measurement model show that the psychometric properties for the latent constructs in the proposed model were good.

Based on the above findings, we can confirm the existence of three dimensions of the cognitive component of the image of a rural tourism destination, which addresses the first research objective.

A hierarchical factor structure was also examined in the research. Figure 2 illustrates the results of the second-order factorial structure for the general image of the rural tourism destination. In Figure 2, as well as Figure 1, each observed variable (FUNCT1, FUNCT2, FUNCT4, FUNCT5, FUNCT6, MIX4, MIX6, PSYCHO1, PSYCHO2, PSYCHO3, PSYCHO4, PSYCHO5, PSYCHO6) has an error term (E1-E18) or measurement error, which reflects their adequacy in measuring the related underlying factors (FUNCT, MIX, PSYCHO). Figure 2 also presents residual errors (E19-E21), which represent errors in prediction of endogenous factors (overall image) from exogenous factors (FUNCT, MIX, PSYCHO).

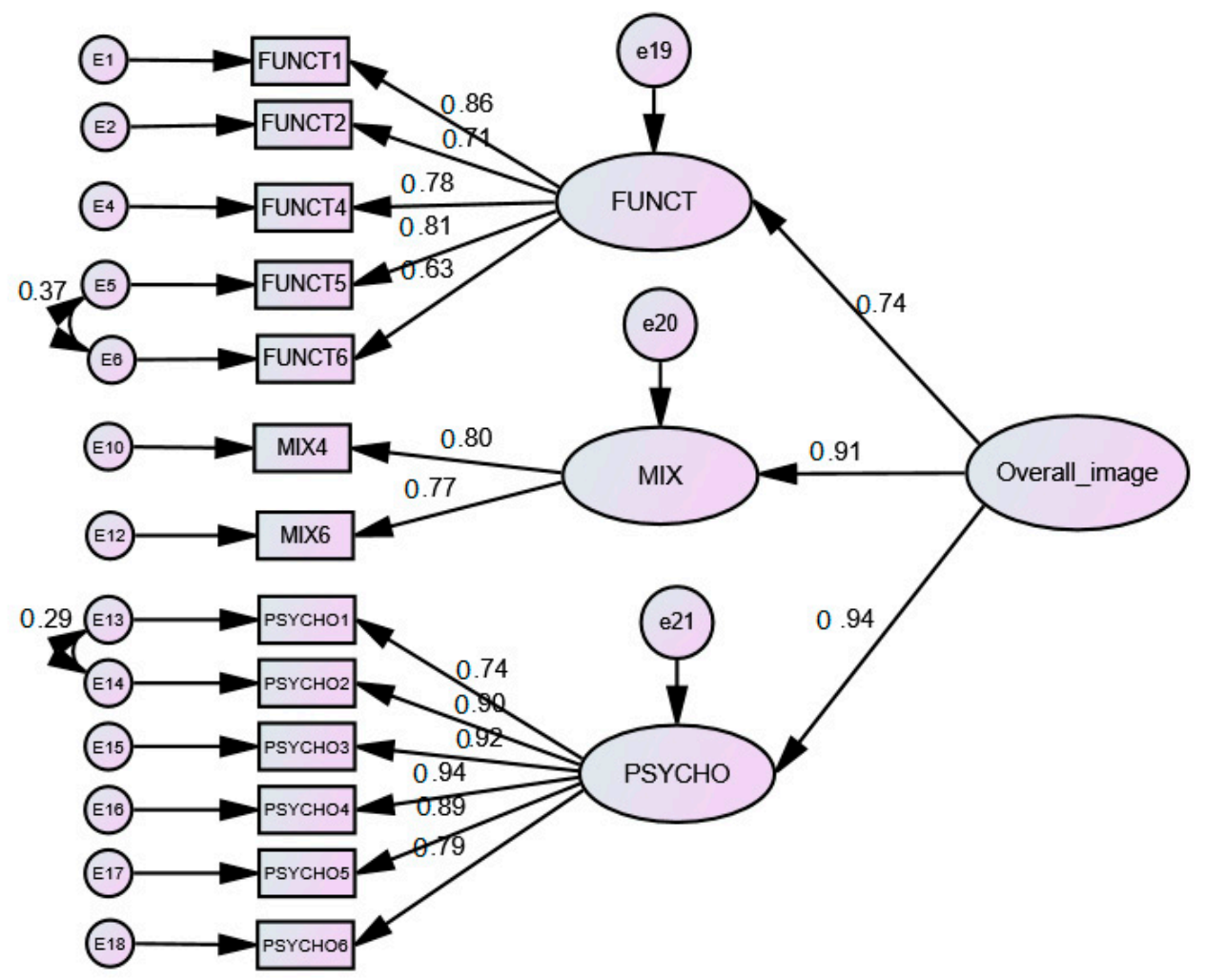

Figure 2. Confirmatory factor analysis-second-order measurement model for the general image of a rural tourism destination.

The path coefficients for the general image of the rural tourism destination varied among three dimensions: functional (0.77), mixed (0.91), and psychological (0.94). It can be concluded that the psychological dimension of the cognitive component of the image of a rural tourism destination makes the greatest, statistically significant $(p<0.001)$ impact on the general image of the rural tourism destination, which addresses the second research objective.

\section{Discussion}

The initial model in this study was generated based on earlier research, which revealed that the image of a rural tourism destination is essentially affected by the cognitive component and its dimensions. After deleting five items, the final three-factor structure was composed of 13 items: 
six items representing the psychological dimension (It is a quiet/peaceful place, Staff and members of the local community provide tourists with warm welcome, It offers personalized service to tourists, It has quality services, It offers good value for money, There is high quality accommodation); five items representing the functional dimension (It is a nice/beautiful place with attractive natural scenery, There are many historical monuments/sites/museums, Tourists can undertake different activities in the countryside, The availability of accommodation is good, The local transport is good); and two items representing the mixed dimension (Partaking in local gastronomic activities/tours is good, Tourists can engage in social interactions with the members of the local community). From these results, we can confirm the existence of three dimensions of the cognitive component of the image of a rural tourism destination.

It should be noted that other authors too have considered many of the abovementioned dimensions. In their content analysis of four tourism destinations, Baloglu and Mangaloglu [52] measured the cognitive component using 14 items (good value for money, attractive surroundings and appealing landscapes, enjoyable climate, edifying cultural sites, comfortable lodging, appetizing local cuisine, exciting water sports, quality of infrastructure, personal safety, historical sites, unpolluted natural resources, good leisure activities, standard hygiene and cleanliness, friendly people). Quintal et al. [53] derived five factors (infrastructure, pastimes, perceived financial risk, local agricultural products, and climate) using 15 items, whereas Kim and Park [54] explored four factors (infrastructure; quality of experience; spots of interest; and value of surroundings, animation, and comfort) using 16 items for the cognitive component of the image of a tourism destination. In addition, while investigating the relationships of the cognitive, affective, and conative components of the tourism destination image, Basaran [41] defined 29 items within six dimensions of the cognitive component (scenery, cultural attraction, social setting and geographic location, infrastructure and facilities, accessibility, price and value). By examining the role of the image of a destination in tourist satisfaction Alcocer and Ruiz [20] composed the cognitive component using eight dimensions (natural resources; general infrastructure; tourism infrastructure; leisure and recreation tourism; culture, history, and art; natural environment; social environment; and political and economic factors).

This study also shows that the psychological dimension of the cognitive component of the image of a rural tourism destination has the most significant impact, followed by the functional dimension. These results are in line with the study of Alcaniz et al. [43], who proposed to explore in more detail the opinions on the functional and psychological continuum of the cognitive component. Similarly, Lin et al. [55] revealed in their study that not all dimensions representing the cognitive component have equal impact on tourists' destination choices. Thus, the final results of the EFA indicated that there were three cognitive dimensions explaining $59.9 \%$ of the variance (natural characteristics, amenities, and infrastructure).

\section{Conclusions}

Understanding the structure of the image of a rural tourism destination contributes significantly to developing a sustainable competitive advantage in the hospitality industry market. Due to the difficulty in measuring sustainability, it is essential to emphasize sustainability as the purpose of tourism and not necessarily the outcome [56]. Sustainable tourism should maintain a high level of tourist satisfaction and, at the same time, raise tourists' awareness about sustainability. Tourists tend to perceive various images that affect their behavior, so pinpointing the components of tourism destination image plays an important role in destination management and marketing. This study focused on the cognitive component of the image of a rural tourism destination, aiming to clarify its dimensions (functional, mixed, and psychological), because understanding these dimensions provides information that can help destination managers and marketers develop sustainable positioning strategies. The development of an appropriate image can contribute to further improvement in the development of the hospitality industry at a particular destination. Furthermore, creating the appropriate image is important because 
a positive image helps in positioning the destination in relation to its competitors. Creating a unique destination image has become imperative in order to survive in a competitive tourism market.

This study has several limitations. First of all, this research explored only the Province of Vojvodina as a typical rural tourism destination. Secondly, the sample included only domestic tourists as respondents. Finally, this study investigated only the cognitive approach to the image of a rural tourism destination. This fact limits the significance of tourism destination image as predictor of future tourist behavior. Future research should conduct this analysis repeatedly at a greater number of destinations and include foreign tourists and residents as well. It could also include more items such as "personal safety", especially having in mind the current situation with the COVID-19 pandemic. Future research could also incorporate the affective component of the image of a rural tourism destination so as to analyze its impact on the general image of a tourism destination.

Author Contributions: All of the authors formulated goals of the research and interpreted available literature; conducting and analyzing research was performed by K.L. and S.T.; while implications, limitations, and future research steps were developed by D.M. and N.V.Ć. All authors have read and agreed to the published version of the manuscript.

Funding: This research received no external funding.

Conflicts of Interest: The authors declare no conflict of interest.

\section{References}

1. Martinez, J.M.G.; Martin, J.M.M.; Fernandez, J.A.S.; Mogorron-Guerrero, H. An analysis of the stability of rural tourism as a desired condition for sustainable tourism. J. Bus. Res. 2019, 100, 165-174. [CrossRef]

2. Fennell, D.A. Ecotourism; Routledge: New York, NY, USA, 2007.

3. Almeida, F.; Pelaez, M.A.; Balbuena, A.; Cortes, R. Residents' perceptions of tourism development in Benalmadena (Spain). Tour. Manag. 2016, 54, 259-274. [CrossRef]

4. Andereck, K.L.; Nyaupane, G.P. Exploring the nature of tourism and quality of life perceptions among residents. J. Travel Res. 2011, 50, 248-260. [CrossRef]

5. Ivanović, V.; Gašić, M.; Simić, J. The Appliocation of Modern Information and Communication Technologies in Tourism. Ann. Fac. Econ. Subot. 2016, 52, 145-156.

6. Gavrila-Paven, I.; Barsan, M.C.; Lia-Dorica, D. Advantages and Limits for Tourism Development in Rural Area. Procedia Econ. Financ. 2015, 32, 1050-1059.

7. Gavrilović, Z.; Maksimović, M. Green Innovations in the Tourism Sector. Strateg. Manag. 2018, $23,36-42$. [CrossRef]

8. Simpson, M.C. Community benefit tourism initiative-A conceptual oxymoron? Tour. Manag. 2008, 29, 1-18. [CrossRef]

9. Okech, R.; Haghiri, M.; George, B.P. Rural tourism as a sustainable development alternative: An analysis with special reference to Luanda, Kenya. Rev. Cult. Tur. 2012, 6, 36-54.

10. Radović, G.; Košić, K.; Demirović, D. Finansiranje kao ključni element strategije održivog razvoja ruralnog turizma u Republici Srbiji. Ekon. Poljopr. 2018, 65, 413-426. [CrossRef]

11. Sivesan, S. Sustainable Tourism Development in Jaffna District. J. Tour. Hosp. 2020, 9, 1-6.

12. Ayazlar, G.; Ayazlar, R.A. Rural Tourism: A Conceptual Approach. In Tourism, Environment and Sustainability; St. Kliment Ohridski University Press: Sofia, Bulgaria, 2015.

13. Bulin, D. Sustainable rural tourism strategies. A tool for development and conservation. Qual. Access Success 2011, 2, 102-111.

14. Dimitrovski, D.D.; Todorović, A.; Valjarević, A. Rural tourism and regional development: Case study of development of rural tourism in the region of Gruža, Serbia. Procedia Environ. Sci. 2012, 14, $288-297$. [CrossRef]

15. Yilmaz, G.O. The Role of Rural Tourism in Rural Development. In Global Issues and Trends in Tourism; St. Kliment Ohridski University Press: Sofia, Bulgaria, 2016.

16. Trukhachev, A. Metodology for Evaluating the Rural Tourism Potentials: A Tool to Ensure Sustainable Development of Rural Settlements. Sustainability 2015, 7, 3052-3070. [CrossRef] 
17. Irshad, H. Rural Tourism-An Overview; Government of Alberta, Agricultural and Rural Development: Alberta, Canada, 2010.

18. Lane, B. Rural Tourism: An overview. In Handbook of Tourism Studies; SAGE Publications: Thousand Oaks, CA, USA, 2009.

19. Grubor, A.; Leković, K.; Tomić, S. Rural Tourism Marketing of the Danube Region. Int. J. Econ. Theory Pract. Soc. Issues Ekonomika 2019, 65, 18-19.

20. Alcocer, N.H.; Ruiz, V.R.L. The role of destination image in tourist satisfaction: The case of a heritage site. Econ. Res. 2020, 33, 2444-2461.

21. Lo, M.C.; Mohamad, A.A.; Songan, P.; Yeo, A.W. Positioning rural tourism: Perspectives from the local communities. Int. J. Trade Econ. Financ. 2012, 3, 59-65. [CrossRef]

22. Kulcsar, N. Rural tourism in Hungary: The key of competitiveness. In Proceedings of the FIKUSZ 09, Symposium for Young Researchers, Faculty of Economics, Budapest, Hungary, 13 November 2009.

23. Fons, M.V.S.; Fierro, J.A.M.; Patino, M.G. Rural tourism: A sustainable alternative. Appl. Energy 2011, 88, 551-557. [CrossRef]

24. Carballo, M.M.; Arana, J.E.; Leon, C.J.; Moreno-Gil, S. Economic valuation of tourism destination image. Tour. Econ. 2015, 21, 741-759. [CrossRef]

25. Stylos, N.; Vassiliadis, C.A.; Bellou, V.; Andronikidis, A. Destination images, holistic images and personal normative beliefs: Predictors of intention to revisit a destination. Tour. Manag. 2016, 53, 40-60. [CrossRef]

26. Assaker, G. Examining a hierarchical model of Australia's destination image. J. Vacat. Mark. 2014, 20, $195-210$. [CrossRef]

27. Lai, K.; Li, X. Tourism destination image: Conceptual problems and definitional solutions. J. Travel Res. 2016, 55, 1-16. [CrossRef]

28. Agapito, D.; Valle, P.; Mendes, J. The cognitive-Affective-Conative model of destination image: A confirmatory analysis. J. Travel Tour. Mark. 2013, 30, 471-481. [CrossRef]

29. Michael, N.; James, R.; Michael, I. Australia's cognitive, affective and conative destination image: An Emirati tourist perspective. J. Islamic Mark. 2018, 9, 36-59. [CrossRef]

30. Zhang, H.; Fu, X.; Cai, L.A.; Lu, L. Destination image and touris loyalty: A meta-analysis. Tour. Manag. 2014, 40, 213-223. [CrossRef]

31. Huang, S.; Gross, M.J. Australia's destination image among mainland Chinese travelers: An exploratory study. J. Travel Tour. Mark. 2010, 27, 63-81. [CrossRef]

32. Kokkali, P.; Koutsouris, A.; Chrysochou, P. Cognitive components of rural tourism destination images: The case of lake Plastiras, Greece. Tourismos 2009, 4, 273-291.

33. Pike, S.; Ryan, C. Destination positioning analysis through a comparison of cognitive, affective and conative perceptions. J. Travel Res. 2004, 42, 333-342. [CrossRef]

34. Pike, S. Destination Marketing; Butterworth-Heinemann: Burlington, MA, USA, 2008.

35. Hallmann, K.; Zehrer, A.; Muller, S. Perceived destination image: An image model for a Winter sports destination and its effect on intention to revisit. J. Travel Res. 2014, 54, 94-106. [CrossRef]

36. San Martin, H.; Rodriguez del Bosque, I.A. Exploring the cognitive-affective nature of destination image and the roll of psychological factors in its formation. Tour. Manag. 2008, 29, 263-277. [CrossRef]

37. Asli, D.; Tasci, A. A semantic analysis of destination image terminology. Tour. Rev. Int. 2009, 13, 1-15.

38. Tasci, A.; Gartner, W. Destination image and its functional relationships. J. Travel Res. 2007, 45, 413-425. [CrossRef]

39. Marine-Roig, E. Destination Image Analytics Through Traveller-Generated Content. Sustainability 2019, 11, 3392. [CrossRef]

40. Chen, J.S. A case of Korean outbound travelers' destination images by using correspondence analysis. Tour. Manag. 2001, 22, 345-350. [CrossRef]

41. Basaran, U. Examining the Relationships of Cognitive, Affective, and Conative Destination Image: A Research on Safranbolu, Turkey. Int. Bus. Res. 2016, 9, 164-179. [CrossRef]

42. Qu, H.; Kim, L.H.; Im, H.H. A model of destination branding: Integrating the concepts of the branding and destination image. Tour. Manag. 2011, 32, 465-476. [CrossRef]

43. Alcaniz, E.B.; Garcia, I.S.; Blas, S.S. The functional-psychological continuum in the cognitive image of a destination: A confirmatory analysis. Tour. Manag. 2009, 30, 715-723. [CrossRef] 
44. Polo Pena, A.I.; Jamilena, D.M.F.; Molina, M.A.R. Validation of cognitive image dimensions for rural tourist destinations: A contribution to the management of rural tourist destinations. J. Vacat. Mark. 2012, 18, 261-273. [CrossRef]

45. Kaiser, H. An index of factorial simplicity. Psychometrika 1974, 39, 31-36. [CrossRef]

46. Marsh, H.W.; Hocevar, D. Application of confirmatory factor analysis to the study of self-concept: First-and higher order factor models and their invariance across groups. Psychol. Bull. 1985, 97, 562-582. [CrossRef]

47. Wheaton, B.; Muthen, B.; Alwin, D.F.; Summers, G.F. Assesing reliability and stability in panel models. Sociol. Methodol. 1977, 8, 84-136. [CrossRef]

48. Hu, L.T.; Bentler, P.M. Cutoff criteria for fit indexes in covariance structure analysis: Conventional criteria versus new alternatives. Struct. Equ. Model. Multidiscip. J. 1999, 6, 1-55. [CrossRef]

49. Kline, R.B. Methodology in the Social Sciences. In Principles and Practice of Structural Equation Modeling; Guilford Press: New York, NY, USA, 2011.

50. Hair, J.F.; Black, W.C.; Babin, B.J.; Anderson, R.E. Multivariate Data Analysis; Cengage Learning: New York, NY, USA, 2019.

51. Fornell, C.; Larcker, D. Structural equation models with unobservable variables and measurement error. J. Mark. Res. 1981, 18, 39-50. [CrossRef]

52. Baloglu, S.; Mangaloglu, M. Tourism destination images of Turkey, Egypt, Greece, and Italy as perceived by US-based tour operators and travel agents. Tour. Manag. 2001, 22, 1-9. [CrossRef]

53. Quintal, V.; Phau, I.; Polczynski, A. Destination brand image of Western Australia's South-West Region: Perceptions of local versus international tourists. J. Vacat. Mark. 2014, 20, 41-54. [CrossRef]

54. Kim, S.; Park, E. First-time and repeat tourist destination image: The case of domestic tourists to Weh Island, Indonesia. Int. J. Tour. Hosp. Res. 2015, 26, 421-433. [CrossRef]

55. Lin, C.H.; Morais, D.B.; Kerstetter, D.L.; Hou, J.S. Examining the Role of Cognitive and Affective Image in Predicting Choice Across Natural, Developed, and Theme-Park Destinations. J. Travel Res. 2007, 46, $183-194$. [CrossRef]

56. Arrage, J.A.; Hady, S.A. Ecotourism and sustainability: Practices of the Lebanese nature-based operators. Hotel Tour. Manag. 2019, 7, 11-23.

Publisher's Note: MDPI stays neutral with regard to jurisdictional claims in published maps and institutional affiliations.

(C) 2020 by the authors. Licensee MDPI, Basel, Switzerland. This article is an open access article distributed under the terms and conditions of the Creative Commons Attribution (CC BY) license (http://creativecommons.org/licenses/by/4.0/). 